\title{
Desain Rancang Bangun Trainer Kit untuk Menentukan Pengaruh Jenis Bahan Tali Terhadap Cepat Rambat Gelombang
}

\author{
Linggar Ayu Octaviani ${ }^{1 *}$, Sri Handono Budi Prastowo², dan Firdha Kusuma Ayu \\ Anggraeni $^{3}$ \\ 1,2,3 Program Studi Pendidikan Fisika, Fakultas Keguruan dan IImu Pendidikan, Universitas Jember \\ Jl. Kalimantan No. 37, Jember, 68121, Indonesia \\ E-mail: alinggar75@gmail.com
}

\begin{abstract}
Abstrak
Tujuan penelitian ini adalah untuk mengetahui desain rancang bangun trainer kit untuk menentukan pengaruh jenis bahan tali terhadap cepat rambat gelombang tali dan pengaruh rapat massa dari jenis bahan tali nilon, rafia, polyester, rami dan satin cina terhadap cepat rambat gelombang tali. Metode penelitian yang digunakan yaitu Research and Development menggunakan desain Nieveen. Pengembangan trainer kit menggunakan mikrokontroler Arduino UNO yang dilengkapi sensor jarak HCSR-04 untuk mengukur panjang gelombang tali. Salah satu ujung tali diikatkan dengan ticker timer dan ujung lainnya diikatkan pada beban gantung yang ditumpukan pada sebuah katrol. Ketika power supply dihidupkan, ticker timer akan bergetar untuk menggerakkan tali yang diikatkan. Tali akan membentuk gelombang transversal. Hasil penelitian ini, desain rancang bangun trainer kit dikembangkan dengan menggunakan mikrokontroler Arduino UNO dan sensor jarak HCSR-04 dapat dinyatakan valid. Terdapat pengaruh rapat massa jenis bahan tali nilon, polyester, satin cina, rafia dan rami terhadap cepat rambat gelombang tali.
\end{abstract}

Kata kunci: Gelombang tali, Arduino UNO, Trainer kit.

\begin{abstract}
The aim of the research is to establish the design of the trainer kit project to determine the effect of the rope material type toward the rope wave velocity and the effect of the type of nylon, raffia, polyester, hemp and chinnese satin rope materials on the velocity of rope wave propagation. The research method used is the Research and Development method using Nieveen design. The development of trainer kit uses an Arduino UNO microcontroller equipped with a proximity sensor HC-SRO4 for measuring the rope wavelength. One point of the rope is tied with a timer ticker and the other is tied to a hanging load which is resting on a pulley. When the power supply is turned on, the timer ticker will vibrate to move the rope that has been tied. The rope will form a transverse wave. The result of this research, the design of trainer kit is development by using micro-controlled Arduino UNO and a proximity sensor HC-SR04 can be declared as a valid result. There are mass convention impacts of the type of rope likely nylon, polyester, raffia, hemp and chinese satin toward the rope wave velocity.
\end{abstract}

Keywords: Wave of rope, Arduino UNO, trainer kit.

\section{PENDAHULUAN}

Media pembelajaran fisika saat ini sangat bervariatif. Salah satunya yaitu menggunakan alat peraga atau biasa kita sebut alat praktikum. Alat peraga yang digunakan juga semakin berkembang pesat selaras dengan IImu Pengetahuan dan Teknologi yang semakin maju. Alat peraga dalam pembelajaran fisika memungkinkan menjadi salah satu alternatif untuk meningkatkan kualitas dalam proses pembelajaran khususnya pada pembelajaran fisika (Prabowo dan Sucahyo, 2018).

Beberapa materi pada pelajaran fisika merupakan suatu materi yang abstrak, salah satunya adalah materi gelombang. Gelombang hanya dapat diketahui dari referensi-referensi tanpa melihat langsung gerak nyata dari gelombang tersebut. Materi gelombang didasari dari konsep atau teori yang telah ada sebelumnya tanpa diimbangi dengan kegiatan praktik karena alat dan bahan praktikum yang 
terbatas (Jumini, 2015).

Gerak gelombang merupakan perpindahan energi dan momentum di dalam ruang ke titik lain tanpa pemindahan materi (Tripler, 1998). Gelombang yaitu getaran yang merambat pada suatu medium atau tanpa medium namun medium rambatnya tidak ikut serta mengalami perambatan (Giancoli, 2001). Berdasarkan kedua sumber tersebut gelombang merupakan suatu getaran yang merambat berupa energi dan momentum melalui atau tidak melalui suatu medium tetapi medium rambatnya tidak ikut merambat.

Salah satu peristiwa gelombang yang dapat diamati oleh indra yaitu panjang gelombang tali. Tetapi proses pengamatannya memerlukan ketelitian. Terkadang sering terjadi kesalahan dalam pengukuran yang mengakibatkan kesalahan pada proses pengukuran. Sehingga hasil yang diperoleh kurang valid. Oleh karena itu, untuk mempermudah dalam pengukuran panjang gelombang ini dapat digunakan perangkat mikrokontroler Arduino UNO agar data yang diperoleh lebih valid dan teliti.

Menurut Prastyo dan Yundra (2018) disebutkan alat peraga simulasi (trainer) adalah suatu alat berupa simulasi yang terdiri dari beberapa komponen untuk mempermudah simulasi berupa fisik. Alasan digunakannya mikrokontroler Arduino UNO karena untuk menjelaskan pengaruh jenis bahan tali terhadap cepat rambat gelombang tali perlu menggunakan sensor. Trainer kit dapat dirancang sesuai dengan kebutuhan pada laboratorium sehingga percobaan yang dirancang dapat lebih fokus untuk memudahkan dalam melakukan percobaan (Widianti, 2018). Penggunaan mikrokontroler Arduino UNO dipilih karena mudah pengoperasiannya dan dapat menjalankan sensor secara bersamaan sehingga lebih efisien.

Ditinjau dari studi pendahuluan, pada praktikum Fisika Dasar II tentang percobaan melde di Program Studi Pendidikan Fisika, Fakultas Keguruan dan IImu Pendidikan Universitas Jember masih menggunakan alat praktikum melde sederhana. Pada alat praktikum tersebut masih ditemukan kesulitan dalam pengukuran panjang gelombang tali karena gerakan gelombang tali yang sangat cepat dan membuat mata tidak fokus saat mengamati letak simpul gelombangnya. Selain itu, pada saat praktikum dilakukan hanya menggunakan satu jenis bahan tali saja, variabel yang dirubah hanya massa beban gantung saja. Hal ini hanya menunjukkan bahwa perubahan massa beban gantung berpengaruh terhadap gaya tegang tali dan cepat rambat gelombang tali. Tetapi belum menunjukkan bahwa adanya perubahan rapat massa tali $(\mu)$ juga berpengaruh terhadap cepat rambat gelombang talinya. Sedangkan pada teori berdasarkan Giancoli (2014) disebutkan bahwa faktor yang mempengaruhi cepat rambat gelombang tali adalah gaya tegang tali $(F)$ dan rapat massa tali $(\mu)$. Rapat massa tali diperoleh dari massa tali dibagi dengan panjang tali. Jika jenis bahan talinya berbeda, maka rapat massa tali juga berbeda. Oleh karena itu, diperlukan sebuah trainer kit atau alat peraga yang mampu menjelaskan pengaruh tersebut berupa alat bantu berbasis mikrokontroler Arduino UNO.

Sudah ada beberapa penelitian yang dilakukan untuk mengembangkan alat peraga untuk mengetahui cepat rambat gelombang tali. Salah satunya dilakukan oleh Agustianti et al. (2015) tentang pengembangan alat praktikum Melde sebagai media pembelajaran fisika SMA yang diperoleh dengan menambahkan pengatur frekuensi dan dapat menampilkan grafik pada komputer. Grafik yang ditampilkan berupa gelombang yang terbentuk dari alat praktikum Melde yang nilai frekuensinya dapat diubah-ubah. Selain Agustianti et al. (2015), penelitian lain juga dilakukan oleh Khomsatun dan Prabowo (2019) tentang pengembangan alat peraga hukum Melde untuk menentukan cepat rambat gelombang sebagai media pembelajaran fisika pada materi gelombang stasioner yang diperoleh bahwa alat peraga hukum Melde yang dikembangkan memiliki persentase kelayakan $86 \%$ dan memiliki kriteria sangat layak digunakan sebagai media pembelajaran gelombang stasioner. Namun alat hasil pengembangan baik oleh Agustianti et al. (2015) maupun Khomsatun dan Prabowo 
(2019) belum menunjukkan apakah jenis bahan tali yang digunakan dapat mempengaruhi cepat rambat gelombang talinya.

Berdasarkan uraian tentang gelombang tali dan hasil penelitian sebelumnya, maka peneliti tertarik melakukan sebuah penelitian mengenai rancang bangun alat peraga atau trainer kit yang dapat menjelaskan atau menunjukkan pengaruh jenis bahan tali terhadap kecepatan gelombang tali. Oleh karena itu, peneliti membuat judul "Desain Rancang Bangun Trainer Kit Untuk Menentukan Pengaruh Jenis Bahan Tali Terhadap Cepat Rambat Gelombang Tali". Diharapkan dengan adanya desain rancang bangun tersebut maka dapat mempermudah dalam melakukan percobaan dan perhitungan cepat rambat gelombang tali serta hasil yang diperoleh lebih valid dan teliti.

\section{METODE EKSPERIMEN}

Penelitian ini dilaksanakan di Laboratorium Fisika Dasar Program Studi Pendidikan Fisika FKIP Universitas Jember. Metode penelitian yang digunakan dalam penelitian ini adalah metode Research and Development $(\mathrm{RnD})$. Desain penelitian yang digunakan adalah desain Nieveen. Menurut Nieveen (2006) tahapannya meliputi 3 kegiatan yaitu 1) Preliminary Research, 2) Prototyping Stage, 3) Assessment Stage. Desain yang digunakan pada tahap penilaian atau assessment (Assessment stage) terhadap produk yang akan dikembangkan adalah menggunakan regresi linier. Regresi linier ini digunakan untuk mengetahui bagaimana presisi atau keakuratan dari alat peraga (trainer kit) yang dikembangkan. Secara sistematis model penelitian pengembangan menurut Nieveen ditunjukkan pada gambar 1 .

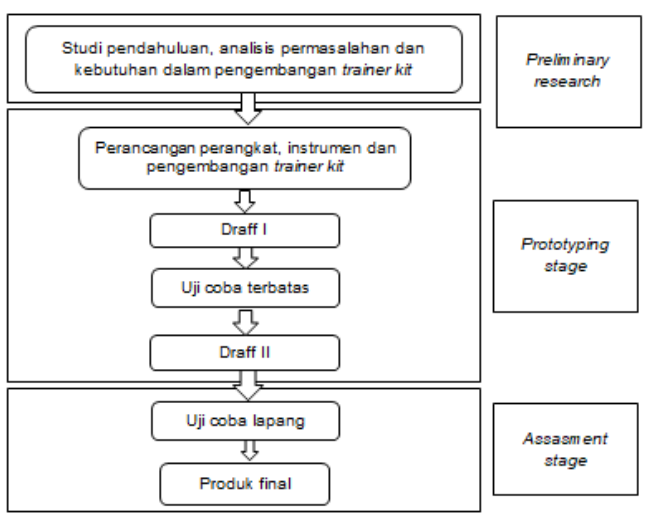

Gambar 1. Bagan modifikasi model pengembangan Nieveen

Pada tahap awal yaitu preliminary research dilakukan studi pendahuluan bertujuan untuk memperoleh gambaran awal yang berhubungan dengan pelaksanaan penelitian. Pada tahap ini peneliti melakukan studi literatur, dilanjutkan dengan menganalisis permasalahan dan kebutuhan dalam melakukan pengembangan alat trainer kit. Pada fase ini, peneliti melakukan pengumpulan kajian teori dari berbagai hasil penelitian yang relevan dengan penelitian yang akan dilaksanakan.

Pada tahap selanjutnya yaitu protyping stage dilakukan pengambilan pengembangan trainer kit pengaruh jenis bahan tali terhadap gelombang tali. Tahap perancangan pada penelitian ini terdiri dari beberapa persiapan diantaranya:

\section{Alat dan Bahan}

Alat dan bahan yang digunakan dalam penelitian desain rancang bangun trainer kit untuk menentukan pengaruh jenis bahan tali terhadap cepat rambat gelombang tali adalah sebagai berikut :
1) Ticker Timer
2) Power Supply
3) Tali
4) Katrol
5) Beban
6) Kayu
7) Arduino UNO
8) Sensor Jarak HC-SR04
9) Kabel port USB dan kabel jumper
10) Laptop
11) LCD LM016L (16x2) 
12) I2C Interface LCD 16x2

\section{Desain Produk}

Desain rancang bangun trainer kit yang digunakan ditunjukkan pada gambar 2 berikut ini.

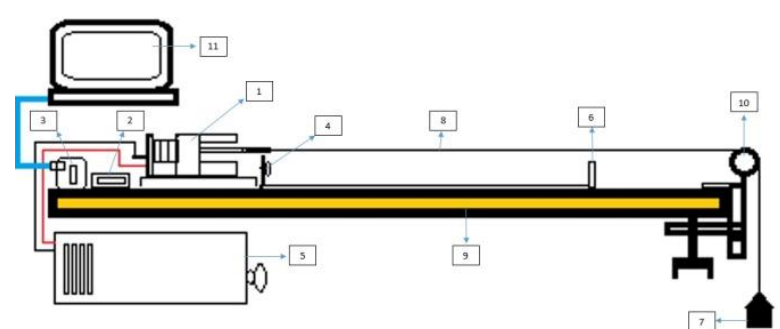

Gambar 2. Rancang bangun trainer kit

Keterangan :

1. Vibrator / ticker timer

2. LCD LM016L (16x2) dan I2C Interface LCD sebagai output panjang gelombang

3. Arduino UNO sebagai mikrokontroler yang digunakan untuk memberi perintah pada sensor.

4. Sensor jarak HC-SR04 sebagai pendeteksi panjang gelombang tali.

5. Power Supply sebagai sumber tegangan

6. Batas sensor sebagai batas ukur dari sensor jarak.

7. Beban gantung

8. Tali sebagai medium rambat gelombang

9. Papan percobaan

10. Katrol

11. Laptop

Rancang bangun trainer kit yang digunakan dilengkapi dengan sistem sensor.

Rangkaian sistem sensor trainer kit ditunjukkan pada gambar 3 di bawah ini.

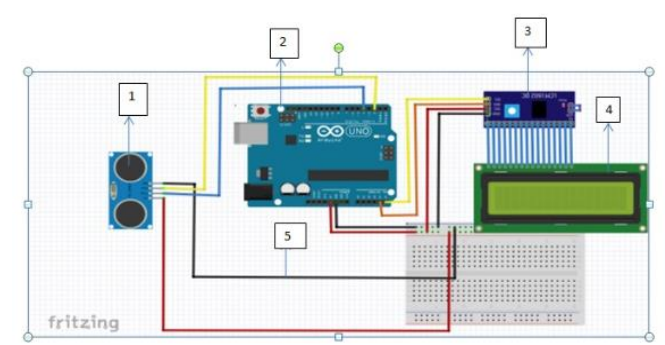

Gambar 3. Skema rangkaian sistem sensor trainer kit

Keterangan :

1. Sensor jarak HC-SR04

2. Arduino UNO

3. I2C LCD Interface

4. LCD

\section{Kabel Jumper}

\section{Uji Coba Terbatas}

Hasil rancangan trainer kit perlu diuji terlebih dahulu sebelum digunakan untuk mengambil data. Pengujian alat ini dilakukan pada masing-masing komponen rangkaian pendukung dari keseluruhan sistem alat. Proses uji coba yang dilakukan yaitu menguji rangkaian sistem trainer kit untuk mengetahui apakah rangkaian sensor berjalan dengan baik dan mendapatkan hasil data yang akurat. Selanjutnya, melakukan uji kalibrasi sensor dengan membandingkan alat yang berasal dari buatan pabrik untuk mengetahui kevalidan pembacaan yang dilakukan oleh sensor.

\section{Evaluasi dan Revisi}

Evaluasi bertujuan untuk menguji kevalidan alat yang berdasarkan analisis menggunakan persamaan regresi linier. Analisis regresi ini akan menganalisis draf I yang telah dibuat pada tahapan desain produk yang nantinya dianalisis linier dan disajikan dalam grafik.

Jika hasil yang diperoleh dari evaluasi dan revisi pada draf I dinyatakan valid, maka produk dapat digunakan untuk tahap selanjutnya. Jika masih belum valid, maka dikatakan belum layak dan harus direvisi. Hasil dari revisi harus dilakukan validasi ulang hingga didapat sebuah produk yang sudah valid dan layak (draf II).

Tahap yang terakhir yaitu tahap penilaian (Assessment Stage). Pada tahap ini dilakukan uji coba lapang terhadap draf II yang diperoleh dari tahap pengembangan sebelumnya dengan menjalankan trainer kit yang telah dirancang. Hal ini dilakukan untuk mengetahui berhasil tidaknya penggunaan produk pengembangan. Kemudian melakukan analisis pada hasil yang diperoleh dari produk pada uji coba. Jika hasil yang didapatkan sesuai dengan teori cepat rambat gelombang tali, maka dihasilkan produk akhir. Jika masih belum sesuai dengan teori, maka akan dilakukan revisi produk dan diujicobakan kembali hingga mendapatkan produk revisi yang sesuai dengan teori. Kemudian membuat kesimpulan mengenai trainer kit dari data yang didapatkan. 


\section{HASIL DAN PEMBAHASAN}

\section{HASIL}

Desain trainer kit untuk menentukan pengaruh jenis bahan tali terhadap cepat rambat gelombang tali dikembangkan dengan menambahkan mikrokontroler Arduino UNO dan sensor jarak HC-SR04 sebagai pengukur panjang gelombang tali. Trainer kit hasil rancangan peneliti ditunjukkan pada gambar 4 di bawah ini.

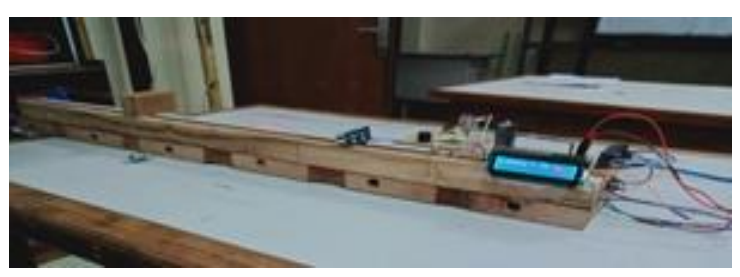

Gambar 4. Trainer kit hasil rancangan peneliti

Selanjutnya, sensor jarak HCSR-04 dikalibrasi terlebih dahulu menggunakan mistar. Tujuan dari kalibrasi sensor jarak HCSR-04 untuk mengetahui kevalidan pembacaan sensor. Hasil kalibrasi sensor jarak HCSR-04 ditunjukkan pada tabel 1 berikut.

Tabel 1. Data kalibrasi sensor jarak HC-SR04

\begin{tabular}{cccc}
\hline No & $\begin{array}{c}\text { Nilai Jarak } \\
\text { Ukur } \\
\text { Mistar } \\
(\mathrm{cm})\end{array}$ & $\begin{array}{c}\text { Nilai Jarak } \\
\text { Ukur } \\
\text { Sensor HC- } \\
\text { SR04 }(\mathrm{cm})\end{array}$ & Error (\%) \\
\hline 1 & 3 & 3,06 & 0,02 \\
2 & 4 & 4,03 & 0,0075 \\
3 & 5 & 4,99 & $-0,002$ \\
4 & 6 & 6,26 & 0,043333333 \\
5 & 7 & 6,49 & $-0,072857143$ \\
6 & 8 & 7,86 & $-0,0175$ \\
7 & 9 & 8,83 & $-0,018888889$ \\
8 & 10 & 9,86 & $-0,014$ \\
9 & 11 & 10,8 & $-0,018181818$ \\
10 & 12 & 11,77 & $-0,019166667$ \\
11 & 13 & 12,73 & $-0,020769231$ \\
12 & 14 & 13,74 & $-0,018571429$ \\
13 & 15 & 14,64 & $-0,024$ \\
14 & 16 & 15,67 & $-0,020625$ \\
15 & 17 & 16,53 & $-0,027647059$ \\
16 & 18 & 17,43 & $-0,031666667$ \\
17 & 19 & 18,51 & $-0,025789474$ \\
18 & 20 & 19,45 & $-0,0275$ \\
\hline
\end{tabular}

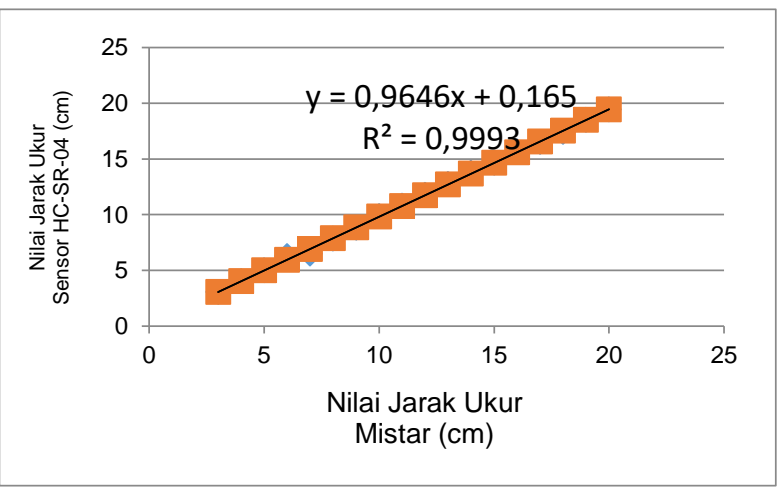

Gambar 5. Grafik Regresi kalibrasi sensor jarak HC-SR04

Pada tabel 1 dan Gambar 5 ditunjukkan hasil kalibrasi sensor jarak HC-SR04 yang telah diolah dengan analisis regresi linier menggunakan Microsoft Excel 2010. Hasil pengolahan analisis regresi linier diperoleh persamaan $y=0,9646 x+0,165$ dengan nilai $R$ square $R^{2}=0,9993 \quad(99,93 \%)$ artinya dari keseluruhan data hasil kalibrasi sensor jarak HC-SR04 dapat dijelaskan oleh regresi, dan masih ada sekitar $0,1 \%$ yang tidak bisa dijelaskan oleh regresi. Dari data tersebut diperoleh nilai error dari pembacaan sensor jarak HC-SR04 sebesar 0,02\% s/d 0,07\%. Hal ini menunjukkan bahwa sensor jarak HC-SR04 telah valid dan dapat menghasilkan data yang benar serta dapat digunakan sebagai alat ukur jarak yang standar.

Selanjutnya, hasil penelitian pengaruh jenis bahan tali terhadap cepat rambat gelombang tali menggunakan panjang tali 0,7 $\mathrm{m}$ dan massa beban gantung $0,02 \mathrm{~kg}$ ditunjukkan pada Tabel 2 dibawah ini.

Tabel 2. Data pengaruh jenis bahan tali terhadap cepat rambat gelombang tali

\begin{tabular}{cccc}
\hline $\begin{array}{c}\text { Jenis } \\
\text { Bahan } \\
\text { Tali }\end{array}$ & $\begin{array}{c}\text { Rapat } \\
\text { Massa Tali } \\
(\mathrm{kg} / \mathrm{m})\end{array}$ & $\begin{array}{c}\text { Panjang } \\
\text { Gelombang } \\
(\mathrm{cm})\end{array}$ & $\begin{array}{c}\text { Cepat } \\
\text { Rambat } \\
\text { Gelomban } \\
\mathrm{g}(\mathrm{m} / \mathrm{s})\end{array}$ \\
\hline \multirow{6}{*}{ Nilon } & 0,000495 & 57,37 & 20,1008 \\
& 0,000495 & 57,57 & 20,1008 \\
& 0,000495 & 57,16 & 20,1008 \\
& 0,000495 & 57,62 & 20,1008 \\
Rafia & 0,000498 & 57,69 & 20,0502 \\
\hline \multirow{2}{*}{ Polyester } & 0,001104 & 48,75 & 13,4595 \\
& 0,001096 & 48,85 & 13,5086 \\
& 0,001104 & 48,73 & 13,4595 \\
& 0,001100 & 48,85 & 13,4840 \\
& 0,001092 & 48,73 & 13,5333 \\
\hline
\end{tabular}




\begin{tabular}{cccc}
\hline $\begin{array}{c}\text { Jenis } \\
\text { Bahan } \\
\text { Tali }\end{array}$ & $\begin{array}{c}\text { Rapat } \\
\text { Massa Tali } \\
(\mathrm{kg} / \mathrm{m})\end{array}$ & $\begin{array}{c}\text { Panjang } \\
\text { Gelombang } \\
(\mathrm{cm})\end{array}$ & $\begin{array}{c}\text { Cepat } \\
\text { Rambat } \\
\text { Gelomban } \\
\mathrm{g}(\mathrm{m} / \mathrm{s})\end{array}$ \\
\hline & 0,001143 & 42,57 & 13,2260 \\
& 0,001143 & 42,55 & 13,2260 \\
& 0,001147 & 42,45 & 13,2068 \\
\hline Rami & 0,001407 & 39,32 & 11,9239 \\
& 0,001407 & 39,30 & 11,9239 \\
& 0,001407 & 39,48 & 11,9239 \\
Satin & 0,001407 & 39,20 & 11,9239 \\
Cina & 0,001410 & 39,22 & 11,9098 \\
\hline & 0,001913 & 27,19 & 10,2240 \\
& 0,001913 & 27,19 & 10,2240 \\
& 0,001913 & 27,75 & 10,2240 \\
& 0,001913 & 27,32 & 10,2240 \\
& & 27,21 & 10,2240 \\
\hline
\end{tabular}

Pada tabel di atas telah diperoleh data panjang gelombang dan cepat rambat gelombang tali masing-masing jenis bahan tali pada percobaan melde. Panjang gelombang tali diperoleh dari pembacaan sensor jarak HC-SR04 yang terdapat pada trainer kit. Sensor jarak HC-SR04 diletakkan pada simpul bukit dan batas sensor diletakkan pada simpul lembah (satu gelombang penuh). Kemudian setiap jenis bahan tali pengukurannya dilakukan secara berulang sebanyak 5 kali, sehingga diperoleh 5 data masing-masing jenis bahan tali. Selanjutnya ganti dengan jenis bahan tali yang lainnya. Kemudian datadata yang telah diperoleh dihitung sehingga mendapatkan nilai cepat rambat gelombang tali pada masing-masing jenis bahan tali yang digunakan. Dari data perhitungan cepat rambat gelombang tali tersebut dapat diperoleh grafik pengaruh jenis bahan tali dengan cepat rambat gelombang tali yang ditunjukkan pada Gambar 6 berikut.

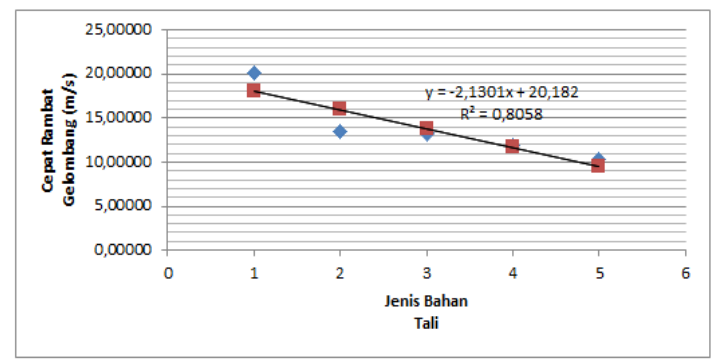

Gambar 6. Grafik pengaruh jenis bahan tali terhadap cepat rambat gelombang tali

Keterangan :

$1=$ Tali Nilon

2 = Tali Rafia

\section{$3=$ Tali Polyester}

$4=$ Tali Rami

$5=$ Tali Satin Cina

Pada gambar grafik di atas telah diperoleh persamaan regresi linier $\mathrm{y}=$ $2,1301 x+20,182$ dan nilai $R$ square $\mathrm{R}^{2}=0,8058$. Persamaan regresi linier tersebut didapatkan dengan cara mensubsitusikan jenis bahan tali dan nilai cepat rambat gelombang. Hal ini menunjukkan bahwa jenis bahan tali berpengaruh terhadap cepat rambat gelombang tali. Pada jenis bahan tali nilon memiliki cepat rambat gelombang tercepat, lalu ada tali rafia, tali polyester, tali rami dan yang paling lambat yaitu cepat rambat gelombang pada tali satin cina. Hal ini disebabkan oleh rapat massa tali dari masingmasing jenis bahan tali berbeda. Rapat massa tali nilon paling ringan, sehingga cepat rambat gelombang talinya semakin cepat. Sedangkan pada tali satin cina memiliki rapat massa tali yang besar, sehingga cepat rambat gelombangnya semakin lambat. Berdasarkan hal tersebut ditunjukkan bahwa hasil data trainer kit rancangan peneliti sesuai dengan hasil penelitian sebelumnya yang dilakukan oleh Jumini (2015) yaitu cepat rambat gelombang pada dawai dipengaruhi oleh rapat massa tali suatu tali sehingga bahwa semakin besar massa tali maka cepat rambat gelombang tali akan semakin kecil (Jumini, 2015). Hubungan antar keduanya yaitu kecepatan rambat gelombang tali (v) berbanding terbalik dengan nilai akar rapat massanya $(\mu)$ atau bisa dituliskan dengan menggunakan persamaan berikut.

$$
v=\sqrt{\frac{F_{T}}{\mu}}
$$

Keterangan :

$$
\begin{aligned}
& v=\text { cepat rambat gelombang tali }(\mathrm{m} / \mathrm{s}) \\
& F_{T}=\text { Gaya tegang tali }(\mathrm{N}) \\
& \mu=\text { Rapat massa tali }(\mathrm{kg} / \mathrm{m})
\end{aligned}
$$

Selain berpengaruh terhadap cepat rambat gelombang tali, jenis bahan tali juga mempengaruhi panjang gelombang tali yang dihasilkan. Pada tabel 2 juga ditunjukkan nilai panjang gelombang tali yang dihasilkan dari masing-masing jenis bahan tali. Nilai panjang gelombang tali diperoleh dari hasil pengukuran menggunakan sensor jarak HC-SR04 yang telah dikalibrasi. Pengukuran dilakukan secara 
berulang sebanyak 5 kali pengulangan. Grafik pengaruh jenis bahan tali terhadap panjang gelombang tali ditunjukkan pada gambar 7 dibawah ini.

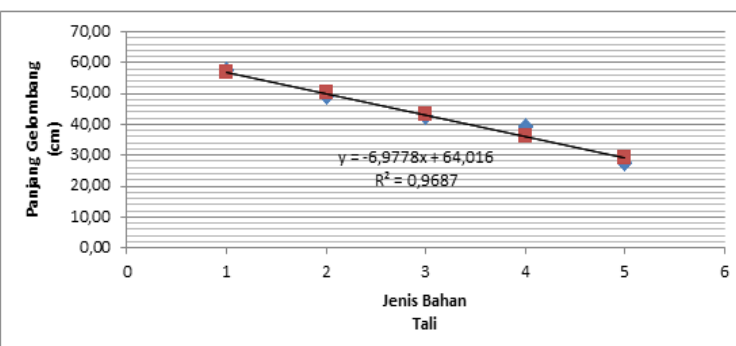

Gambar 7. Grafik pengaruh jenis bahan tali terhadap panjang gelombang tali

Pada gambar 4 telah ditunjukkan grafik pengaruh jenis bahan tali terhadap panjang gelombang tali dan diperoleh persamaan regresi linier $y=-6,9778 x+64,016$ dengan nilai $R^{2}=0,9687$ artinya seluruh variasi jenis bahan tali terhadap panjang gelombang yang dihasilkan berpengaruh sebesar 96,87\%, sedangkan sisanya $3,13 \%$ dipengaruhi oleh faktor lain yang tidak termasuk variabel yang diteliti. Persamaan regresi linier tersebut didapatkan dengan cara mensubsitusikan jenis bahan tali dan nilai panjang gelombang hasil pengukuran menggunakan sensor jarak HCSR-04. Grafik tersebut menunjukkan bahwa semakin besar nilai rapat massa tali suatu bahan tali maka panjang gelombang tali akan semakin pendek karena tali akan semakin susah bergerak naik turun. Hal tersebut sesuai dengan salah satu faktor yang mempengaruhi cepat rambat gelombang berdasarkan Halpern, yaitu semakin besar massa dari suatu tali maka semakin susah tali tersebut untuk bergerak (Halpern dan Eerlbach, 1998).

\section{PEMBAHASAN}

Penelitian ini diawali dari tahap Preliminary Research yaitu dengan melakukan kajian literatur yang dapat mendukung penelitian. Selanjutnya ke tahap kedua yaitu Protyping Stage. Pada tahap ini peneliti melakukan perancangan trainer kit. Pertama, peneliti menyiapkan alat dan bahan yang akan digunakan dalam penelitian. Kemudian mulai membuat rancangan bangun trainer kit yang terdiri dari rancangan bentuk fisik trainer kit berupa papan kayu yang di hubungkan dengan ticker timer dan katrol diujungnya, di samping ticker timer terdapat rel sebagai tempat berjalannya sensor jarak HCSR04. Setelah rancang bangun fisik selesai, dilanjutkan dengan merancang sistem sensor yang akan diletakkan pada rancang bangun fisik trainer kit. Rancangan sistem sensor menggunakan pengendali berupa mikrokontroler Arduino UNO. Arduino akan mengendalikan sensor yang digunakan yaitu sensor jarak HC-SR04. Pada perancangan sistem sensor trainer kit dimulai dengan membuat prototype rangkaian sistem alat menggunakan software fritzing 0.9.3b. Selanjutnya peneliti melakukan perancangan sistem sensor sesuai desain yang telah dibuat menggunakan software fritzing tersebut. Setelah rancangan sistem selesai kemuan membuat program pada Arduino UNO menggunakan software IDE Arduino. Setelah program yang dibuat telah benar langsung upload program ke dalam papan mikrokontroler Arduino UNO. Setelah perancangan fisik dan sistem sensor telah sesuai, selanjutnya memasang rancangan sistem sensor pada rancangan bangun trainer kit yang dibuat.

Setelah pemasangan selesai kemudian melakukan uji coba terbatas untuk mengetahui keakuratan alat yang telah dibuat. Uji coba terbatas dilakukan dengan pengkalibrasian sensor yang digunakan dengan alat standar buatan pabrik. Oleh karena itu, diharapkan setelah melalui proses kalibrasi trainer kit dapat dinyatakan valid dan sudah dapat digunakan.

Sensor yang digunakan pada trainer kit rancangan peneliti adalah sensor jarak HCSR04. Kalibrasi sensor jarak HC-SR04 dilakukan dengan membandingkan alat ukur sensor jarak HC-SR04 dengan alat ukut mistar. Dari hasil kalibrasi peneliti memperoleh 18 data hasil ukur sesuai dengan tabel 4.1 dengan nilai error sebesar $0,02 \%-0,07 \%$. Data kalibrasi yang diperoleh kemudian dianalisis regresi dengan menggunakan Microsoft Excel 2010 sehingga didapatkan grafik hasil regresi. Pada grafik hasil regresi, 
data yang diperoleh nilai $R$ Square 0,9993 artinya dari keseluruhan data kalibrasi sensor jarak HC-SR04 dapat dijelaskan oleh regresi sebesar 99,93\% dan sisanya 0,07\% dipengaruhi oleh faktor lain yang tidak termasuk variabel yang diteliti. Hal ini menunjukkan bahwa data hasil yang diperoleh sensor jarak sudah sesuai dengan alat standar buatan pabrik yaitu mistar.

Dari hasil kalibrasi yang telah dilakukan peneliti, trainer kit rancangan peneliti dapat dinyatakan valid dan dapat dilanjutkan ke tahap berikutnya. Tahap selanjutnya yaitu Assesment Stage yang diawali dengan uji coba lapang. Uji coba lapang dilakukan di Laboratorium Fisika Dasar Program Studi Pendidikan Fisika FKIP Universitas Jember. Uji coba dilakukan di pagi hari yaitu pada hari Kamis, 19 Desember 2020. Uji coba lapang dilakukan dengan 5 variasi jenis bahan tali. Jenis bahan tali yang digunakan antara lain tali nilon, polyester, rami, rafia dan satin cina. Variasi jenis bahan tali digunakan untuk mengetahui pengaruh jenis bahan tali nilon, polyester, rami, rafia dan satin cina terhadap hasil perhitungan cepat rambat gelombang tali.

Pada uji coba trainer kit peneliti menetapkan beberapa variabel kontrol diantaranya massa beban gantung yaitu sebesar 20 gram atau $0,02 \mathrm{~kg}$. Sehingga gaya tegang talinya sebesar $0,2 \mathrm{~N}$. Tegangan ( $\mathrm{V}$ dari power supply yang dihubungkan pada ticker timer sebesar $9 \mathrm{~V}$ dengan besar arus listrik $6 \mathrm{~A}$, percepatan gravitasi bumi sebesar $10 \mathrm{~m} / \mathrm{s}^{2}$ serta panjang tali $70 \mathrm{~cm}$ atau $0,7 \mathrm{~m}$. Massa tali diukur menggunakan neraca digital dengan ketelitian 0,01 gram dan dilakukan berulang sebanyak 5 kali pengukuran. Rapat massa tali $(\mu)$ diperoleh dari perhitungan menggunakan persamaan 2.1. Lalu diperoleh rapat massa dari jenis bahan tali nilon, rafia, polyester, rami dan satin cina ditunjukkan pada tabel 4.2. Dari perhitungan rapat massa tali dari jenis bahan tali tersebut diperoleh bahwa rapat massa tali dari masing-masing jenis bahan tali berbeda nilainya. Rapat massa tali terbesar adalah tali dari bahan satin cina dengan rata-rata nilai rapat massa tali $0,001913 \mathrm{~kg} / \mathrm{m}$, selanjutnya ada tali rami dengan rata-rata nilai rapat massa tali
$0,001407 \mathrm{~kg} / \mathrm{m}$, lalu tali polyester dengan ratarata nilai rapat massa tali $0,0011467 \mathrm{~kg} / \mathrm{m}$, tali rafia dengan rata-rata nilai rapat massa tali $0,001099 \mathrm{~kg} / \mathrm{m}$ dan tali nilon dengan rata-rata nilai rapat massa tali $0,000496 \mathrm{~kg} / \mathrm{m}$. Selanjutnya tali nilon, rafia, polyester, rami dan satin cina dihubungkan pada ticker timer dan ditumpukan pada katrol di ujung dan diberi beban gantung sebesar 20 gram (dilakukan secara bergantian satu per satu). Ketika power supply dihidupkan maka ticker timer akan bergetar menggerakkan tali sehingga membentuk gelombang transversal. Selanjutnya, mulai menggeser sensor jarak HC-SR04 lurus dengan simpul bukit dan batas sensor digeser tepat di simpul lembah atau sebaliknya untuk mengukur panjang gelombang tali. Uji pengambilan data awal menggunakan tali nilon. Selanjutnya diulang dengan menggunakan variasi tali yang lain, yaitu polyester, rafia, rami dan satin cina. Data yang diperoleh ditunjukkan pada tabel 4.2, dapat diamati bahwa dari kelima variasi bahan tali yang digunakan terjadi perubahan pada panjang gelombang tali dan cepat rambatnya. Berdasarkan Giancoli (2001: 383) cepat rambat gelombang tali yang terentang maupun pada dawai bergantung pada tegangan tali dan rapat massa talinya. Dari kelima variasi bahan tali yang digunakan memiliki perbedaan pada rapat massa talinya.

Analisis data hasil uji coba trainer kit menunjukkan semakin besar rapat massa tali dari bahan tali maka semakin cepat rambat gelombangnya semakin menurun seperti pada gambar 4.4. Pada grafik analisis regresi yang ditunjukkan gambar 4.4 diperoleh persamaan regresi liniernya $y=-2,1301 x+20,182$. Kemudian diperoleh nilai $R$ Square $\left(\mathrm{R}^{2}=\right.$ 0,8058 ) artinya keseluruhan variasi jenis bahan tali yang digunakan berpengaruh terhadap cepat rambat gelombang talinya sebesar 80,58\%, sedangkan 19,42\% dipengaruhi oleh faktor lain yang tidak termasuk dalam variabel yang diteliti. Grafik tersebut menunjukkan bahwa semakin besar nilai rapat massa tali suatu bahan tali maka cepat rambat gelombang tali akan melambat. Berdasarkan hal tersebut ditunjukkan bahwa hasil data trainer kit rancangan peneliti sesuai 
dengan hasil penelitian sebelumnya yang dilakukan oleh Jumini (2015) yaitu cepat rambat gelombang pada dawai dipengaruhi oleh rapat massa tali suatu tali sehingga bahwa semakin besar massa tali maka cepat rambat gelombang tali akan semakin kecil.

Selain berpengaruh terhadap cepat rambat gelombang tali, ternyata jenis bahan tali juga berpengaruh terhadap panjang gelombang tali yang dihasilkan. Panjang gelombang tai diukur menggunakan sensor jarak HC-SR04. Berdasarkan tabel 4.2 dapat digambarkan grafik pengaruh jenis bahan tali terhadap panjang gelombang tali pada gambar 4.6. Salah satu faktor yang mempengaruhi kecepatan rambat gelombang berdasarkan Halpern (1998:5) yaitu semakin besar massa tali maka semakin susah untuk bergerak naik turun. Sehingga panjang gelombangnya juga semakin pendek.

Pada grafik analisis regresi yang ditunjukkan pada gambar 4.6 diperoleh persamaan regresi liniernya $y=-6,9778 x+$ 64,016 . Kemudian diperoleh nilai $R$ Square $\left(R^{2}=0,9687\right)$ artinya seluruh variasi jenis bahan tali yang digunakan berpengaruh sebesar $96,87 \%$ terhadap panjang gelombang yang dihasilkan, sedangkan sisanya $3,13 \%$ dipengaruhi oleh faktor lain yang tidak termasuk variabel yang diteliti dalam penelitian ini. Grafik tersebut menunjukkan bahwa semakin besar nilai rapat massa tali suatu bahan tali maka panjang gelombang tali akan semakin pendek karena tali akan semakin susah bergerak naik turun. Dari data pada tabel 4.2 maka dapat diketahui hubungan antara rapat massa jenis bahan tali terhadap panjang gelombang tali adalah berbanding terbalik sesuai dengan persamaan berikut ini :

$$
\begin{aligned}
& v=\sqrt{\frac{F_{T}}{\mu}} \\
& v=\sqrt{\frac{F_{T}}{\frac{m_{t}}{l}}}
\end{aligned}
$$

Berdasarkan Jumini (2015) apabila menggunakan persamaan $v=\lambda \mathrm{xf}$ dan $F_{T}=$ $m_{b} \times g$, maka dapat diperoleh :

$$
\begin{aligned}
& \lambda \mathrm{xf}=\sqrt{\frac{m_{b} \times g}{\frac{m_{t}}{l}}} \\
& \lambda=\sqrt{\frac{m_{b} \times g}{\mu}} x f
\end{aligned}
$$

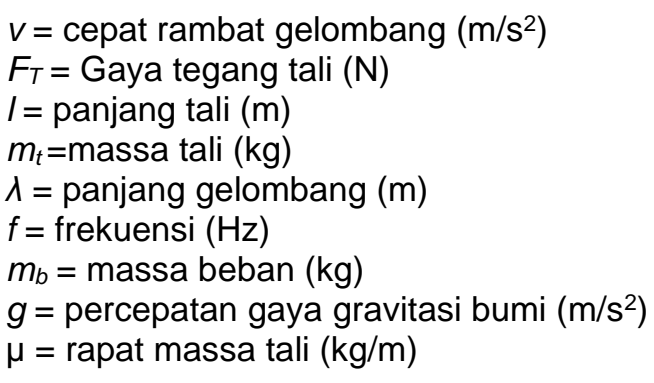

\section{PENUTUP}

\section{KESIMPULAN}

Berdasarkan data hasil penelitian yang telah diperoleh oleh peneliti, maka dapat disimpulkan desain rancang bangun trainer kit untuk menentukan pengaruh jenis bahan tali terhadap cepat rambat gelombang tali hasil rancangan peneliti dikembangkan dengan menggunakan mikrokontroler Arduino UNO dilengkapi dengan sensor jarak HC-SR04 untuk mengukur panjang gelombang tali yang dihasilkan dari gelombang tali dapat dinyatakan valid dan bisa digunakan sebagai alat yang standar.

Terdapat pengaruh rapat massa dari jenis bahan tali nilon, tali polyester, tali satin cina, tali rafia dan tali rami terhadap cepat rambat gelombang tali. Hasil penelitian menunjukkan jenis bahan tali yang memiliki rapat massa paling ringan adalah tali nilon, sehingga cepat rambat gelombangnya semakin cepat. Sedangkan jenis bahan tali yang memiliki rapat massa tali terbesar adalah tali satin cina sehingga memiliki cepat rambat gelombang paling lambat.

\section{SARAN}

Berdasarkan pada hasil data yang diperoleh oleh peneliti terdapat beberapa saran, yaitu :

1. Pada pengembangan trainer kit hanya memvariasikan jenis bahan tali tetapi belum memvariasikan panjang tali pada masing-masing bahan tali, oleh karena itu kami berharap hal ini bisa disempurnakan pada penelitian selanjutnya.

2. Perlu ketelitian dan kecermatan dalam meletakkan sensor jarak HC-SR04 dan pembatasnya agar memperoleh data panjang gelombang yang lebih valid. 


\section{REFERENSI}

Agustianti, D., C. E. Rustana., dan H. Nasbey. (2015). Pengembangan Alat Praktikum Melde Sebagai Media Pembelajaran Fisika SMA. Prosiding Seminar Nasional Fisika 2015. Vol. IV. Oktober 2015: 4548.

Giancoli, D. C. (2001). Fisika (5 ed., Vol. 1). (H. H. Wibi, Penyunt., \& Y. Hanum, Penerj.) Jakarta: Erlangga.

Giancoli,D. C. (2014). Fisika : Prinsip dan Aplikasi Edisi ke 7 Jilid 1. Jakarta: Erlangga.

Halpern, A., E. Erlbach. (1998). Schaum's Outline of Theory and Problems of beginning physics II : Waves, Electromagnetism, Optics, and Modern Physics. United States of America : The McGraw-Hill Companies, Inc.

Jumini, S. (2015). Pengaruh Cepat Rambat Gelombang Terhadap Frekuensi Pada Tali. Jurnal Penelitian dan Pengabdian Kepada Masyarakat UNSIQ, 2(3), 151158.

https://doi.org/10.32699/ppkm.v2i3.359

Khomsatun, M. A., Prabowo. (2019). Pengembangan Alat Peraga Hukum Melde Untuk Menentukan Cepat Rambat Gelombang Sebagai Media Pembelajaran Fisika Pada Materi Gelombang Stasioner. Inovasi Pendidikan Fisika, 8(3).

Nieveen, N., McKenney, S., \& van den Akker, J. (2006). Educational design research: the value of variety. In Educational design research (pp. 163-170). Routledge.

Prabowo, F. L., \& Sucahyo, I. (2018). Pengembangan media hukum melde berbasis aplikasi physics toolbox sensor suite pada materi gelombang stasioner. Inovasi Pendidikan Fisika, 7(2): 165-170.

Prastyo A. dan E. Yundra. (2018). Pengembangan trainer kit berbasis ATMega 16 pada mata pelajaran teknik pemrograman di smkn 1 arosbaya. Jurnal Pendidikan Teknik Elektro. 7(2): 127-133.
Tipler, P. A. (1998). Fisika Untuk Sains dan Teknik. Edisi 3 Jilid 1. Jakarta: Erlangga.

Widianti, S. Y. (2018). Pembuatan Trainer kit Berbasis Arduino dengan SMS Gateway Sebagai Modul Praktikum. Prosiding Seminar Nasional Politeknik Negeri Lhoksumawe. II(1): 263. 